\title{
Optimalisasi Pemasangan Panel Solar Home System Untuk Kehidupan Masyarakat Pedesaan di Ban Kubu Karangasem
}

\author{
I Md Aditya Nugraha ${ }^{1}$, Pt Aries Ridhana ${ }^{2}$, Kadek Listuayu ${ }^{3}$
}

\begin{abstract}
The power and energy output of a Solar Power Plant or Solar Home System is influenced by several factors, such as temperature, solar radiation, solar panel orientation, solar panel angle, and Earth's atmosphere. From six samples of SHS in Desa Ban Kubu Karangasem using Friedman Analysis, and continued with Post Hoc Wilcoxon test, the result $p$ is $<0.001$. The results show that there is a significant difference for the voltage, current, power and energy produced by each SHS. This difference is due to the installation of different solar panels. The difference causes the electric energy generated by SHS is different, thus affecting the electrical energy needs and people's lives every day. To optimize it, it is necessary to improve the angle and orientation of the solar panel to $8^{\circ}$ to the North according to the latitude position of the area. On the other hand, in the planning and development of SHS for rural communities in the future needs to be more optimized, so that the utilization of energy produced can be enjoyed by the community optimally and efficiently
\end{abstract}

Key Words : Solar Home System, Rural Electrification, Renewable Energy, Optimization

Intisari - Output daya dan energi suatu PLTS atau Solar Home System dipengaruhi oleh beberapa faktor, antara lain temperatur, intesitas cahaya matahari, orientasi panel surya, sudut kemiringan panel surya, dan keadaan atmosfer bumi. Dari enam sampel SHS di Desa Ban Kubu Karangasem dengan menggunakan Analisis Friedman, dan dilanjutkan dengan Uji Post Hoc Wilcoxon didapatkan hasil $p<0,001$. Hasil tersebut menunjukan bahwa terdapat perbedaan yang bermakna untuk tegangan, arus, daya dan energi yang dihasilkan setiap SHS. Perbedaan ini disebabkan karena pemasangan panel surya yang berbeda. Perbedaan tersebut menyebabkan energi listrik yang dihasilkan SHS berbeda, sehingga mempengaruhi kebutuhan energi listrik dan kehidupan masyarakat setiap hari. Untuk mengoptimalkannya, maka perlu adanya perbaikan pada sudut kemiringan dan arah orientasi panel surya menjadi $8^{\circ}$ ke arah Utara sesuai dengan posisi lintang dari daerah tersebut. Di lain pihak dalam perencanaan dan pembangunan SHS untuk masyarakat pedesaan ke depannya perlu lebih dioptimalkan, sehingga pemanfaatan energi yang dihasilkan dapat dinikmati oleh masyarakat secara optimal dan berdaya guna.

Kata Kunci - Solar Home System, Listrik Pedesaan, Energi Terbarukan, Optimasi

1 Dosen Teknik Elektromedik, Institut Ilmu Kesehatan Medika Persada Bali, Tantular Barat, Denpasar Bali. Telp. 03614747770; email: imdadityanugraha@gmail.com

2 Dosen Teknik Elektromedik, Institut Ilmu Kesehatan Medika Persada Bali, Tantular Barat, Denpasar Bali. Telp. 03614747770; email: aris.ridhana@yahoo.com

3 Dosen Teknik Elektromedik, Institut Ilmu Kesehatan Medika Persada Bali, Tantular Barat, Denpasar Bali. Telp. 03614747770; email: kadeklis91@gmail.com

$$
\text { I. PENDAHULUAN }
$$

Energi surya merupakan salah satu energi terbarukan yang terdapat di alam yang jumlahnya tidak terbatas. Pemanfaatan energi ini hampir setiap waktu, kecuali ketika cuaca buruk dan di malam hari. Pemanfaatan energi surya telah dimanfaatkan dari dulu hingga saat ini, baik itu untuk mengeringkan hasil panen dan menjemur berbagai keperluan sehari-hari. Selain pemanfaatan tersebut, energi surya juga dapat dimanfaatkan sebagai sumber energi untuk menghasilkan energi listrik.

Indonesia memiliki potensi energi surya sebesar 4,8 $\mathrm{kWh} / \mathrm{m}^{2}$ [1]. Besarnya potensi ini menyebabkan Indonesia dapat memanfaatkannya sebagai sumber energi listrik, terutama untuk daerah-daerah terpencil yang belum dijangkau jaringan listrik PLN. Pemanfaatan energi surya sebagai sumber energi listrik dapat kita peroleh dengan mengkonversi energi surya tersebut dengan menggunakan panel surya, baik dengan PLTS Terpusat dan Solar Home System (SHS) [2].

Pemanfaatan SHS sebagai pembangkit tenaga listrik dengan memanfaatkan energi Matahari sudah dilakukan sejak awal dekade 80-an. Sistem ini memiliki kapasitas 25-50 Wp, sehingga dalam mencatu daya dengan kebutuhan besar sangat terbatas. Umumnya sistem ini ditujukan untuk masyarakat pedesaan yang belum memperoleh jaringan listrik PLN. Penggunaan SHS sebagai penerangan digunakan sebagai pengganti penerangan dari lampu tradisional yang berbahan bakar minyak [3].

Pemanfaatan SHS di Indonesia dapat ditemukan di Bali, yaitu di Desa Ban, Kecamatan Kubu, Kabupaten Karangasem. SHS ini bekerja secara stand alone, dimana setiap unit SHS terdiri dari sebuah panel surya $50 \mathrm{Wp}$, sebuah box control unit, baterai $70 \mathrm{Ah}$, dan dilengkapi dengan tiga buah titik lampu. SHS ini merupakan bantuan dari Kementerian Daerah Tertinggal pada tahun 2008 dan 2009, dengan SK Bupati Karangasem No. 363 tahun 2008 dan No 526 tahun 2009 [4].

Berdasarkan penelitian yang telah dilakukan sebelumnya, yaitu Studi Dampak Ekonomi Dan Sosial PLTS Sebagai Listrik Pedesaan Terhadap Masyarakat Desa Ban Kubu Karangasem Bali, oleh I Made Aditya Nugraha, penggunaan SHS berdampak terhadap kehidupan sosial dan ekonomi masyarakat. Hal ini dapat dilihat dari adanya peningkatan dalam bidang ekonomi, kesehatan, pendidikan, keamanan, dan kegiatan keagamaan masyarakat [4]. Meskipun demikian pada saat cuaca baik lamanya energi dari SHS yang dapat dinikmati oleh masyarakat sangat bervariasi, antara $2-3$ jam per hari, namun jika cuaca tidak baik energi listrik dari $S H S$ hanya bertahan selama 0,5 jam atau tidak dapat dimanfaatkan sama sekali.

\section{STUDI LITERATUR}

\subsection{Solar Home System}


Pembangkit Listrik Tenaga Surya (PLTS) adalah sistem pembangkit energi listrik yang mengkonversikan energi foton dari surya menjadi energi listrik. Konversi energi ini terjadi pada sel-sel photovoltaik yang terdapat pada panel surya. Selsel ini terdiri dari lapisan-lapisan tipis dari silikon (Si) murni dan berbagai bahan semi konduktor [5].

PLTS memanfaatkan energi surya secara langsung untuk menghasilkan listrik Direct Current (DC), dan dengan bantuan inverter listrik yang dihasilkan dapat diubah menjadi listrik Alternative Current (AC) apabila diperlukan. Umumnya PLTS merupakan suatu sistem pembangkit tenaga listrik yang dapat memenuhi kebutuhan listrik dari skala kecil (Solar Home System) hingga yang besar, baik secara hybrid atau mandiri.

Solar Home System (SHS) pada umumnya merupakan sistem PLTS dengan ukuran yang lebih kecil, yang ditujukan kepada daerah-daerah terpencil yang belum memperoleh listrik atau jaringan listrik PLN. Sistem ini bekerja secara stand alone, dan pada umumnya terdiri dari sebuah panel surya $50 \mathrm{Wp}$, sebuah box control unit, baterai $70 \mathrm{Ah}$, dan dilengkapi dengan tiga buah titik lampu [3][4].

2.2 Hal-Hal Yang Mempengaruhi Output Energi Solar Home System

Kemampuan menghasilkan energi listrik pada Solar Home System dipengaruhi oleh oleh beberapa hal [2][6][7][8][9]:

1. Temperatur

Sebuah sel surya dapat beroperasi secara maksimum jika temperatur yang diterima sel surya tetap normal sesuai dengan suhu kerja. Kenaikan temperatur melebihi temperatur normal pada sel surya akan melemahkan tegangan open circuit $\left(V_{O C}\right)$ yang dihasilkan, namun arus yang dihasilkan tidak praktis berubah. Perubahan ini menyebabkan kemampuan panel surya untuk menghasilkan energi listrik berubah.

2. Radiasi Matahari

Radiasi Matahari di Bumi tergantung pada keadaan spectrum sel surya ke Bumi. Pengaruh radiasi matahari menyebabkan arus yang dihasilkan panel surya mengalami perubahan. Semakin tinggi radiasi yang diterima, maka arus yang dihasilkan akan meningkat secara proposional. Sedangkan dengan kondisi tanpa beban perubahan tegangan yang dihasilkan sangat kecil.

3. Orientasi panel surya

Orientasi dari panel surya terhadap matahari merupakan suatu hal yang penting untuk panel surya agar dapat menghasilkan energi maksimum. Untuk daerah dengan lokasi terletak di belahan Bumi bagian Selatan maka panel surya diorientasikan ke Utara, begitu juga sebaliknya.

4. Sudut kemiringan panel surya

Penentuan tilt angle sangat penting untuk mendapatkan energi pada nilai yang optimal. Oleh karena itu maka pemasangan panel surya harus dipertahankan agar tegak lurus terhadap sinar Matahari yang jatuh menuju permukaan panel surya. Namun, datangnya sinar matahari yang diterima oleh panel surya selalu bervariasi setiap hari disebabkan karena garis lintang dan deklinasi matahari

I Md Aditya Nugraha : Optimalisasi Pemasangan Panel Solar ... sepanjang tahun. Pengaruh sudut kemiringan terhadap panel surya dapat dilihat pada Gambar 1.

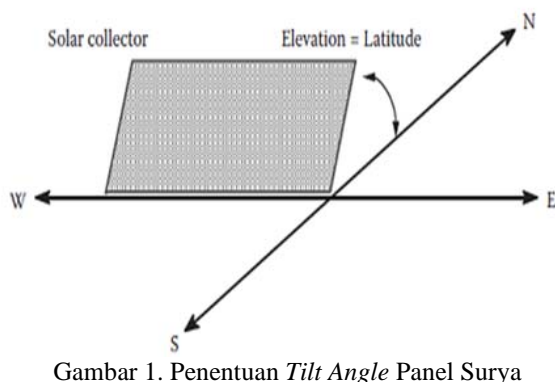

5. Keadaan atmosfir Bumi

Keadaan atmosfir Bumi yang berubah-ubah, seperti mendung, berawan, beruap, berdebu, berasap, berkabut dan berpolusi, akan mempengaruhi hasil maksimum arus listrik dari sel surya.

\subsection{Pelaksanaan Program Listrik Pedesaan}

Kondisi dan bentuk topografi wilayah Indonesia, terutama untuk daerah pedesaan yang tersebar secara luas menyebabkan timbul suatu kegiatan untuk pembangunan program listrik pedesaan. Dimulai dari tahap persiapan, pembangunan fisik sampai tahap operasi pemeliharaannya. Salah satu bentuk kebijakan yang diambil oleh Direktorat Jendral Ketenagalistrikan (DJK) dan PLN dalam pembangunan listrik desa adalah untuk memenuhi rasio elektrifikasi yang meningkat setiap tahun.

Secara umum tujuan dari pelistrikan daerah pedesaan, dapat disusun beberapa faktor penting dalam usaha memberikan listrik kepada desa-desa, terutama untuk negara berkembang, yaitu sebagai berikut [3][4][6]:

1. Program ini dapat mendorong pembangunan pertanian atau perkebunan di daerah pedesaan, serta kegiatan unsur jasa lainnya misalnya sarana kredit pedesaan.

2. Program ini dapat menjadi penggerak bagi kegiatan agro idustri dan kegiatan perdagangan dan selanjutnya akan meningkatkan penggunaan energi listrik untuk kegiatan yang lebih produktif.

3. Program ini dapat meningkatkan kesejateraan hidup masyarakat pedesaan, khusunya dalam menikmati sarana hiburan seperti TV dan radio.

4. Program ini dapat meningkatkan kemampuan masyarakat pedesaan dalam kegiatan membaca dan pendidikan, sehingga dapat meningkatkan daya saing dan mengurangi tingkat buta huruf.

5. Program ini dapat meningkatan kesempatan bekerja dan mengurangi urbanisasi.

6. Program ini dapat meningkatkan kesehatan masyarakat. Hal ini karena masyarakat sudah tidak menggunakan lampu penerangan dari lampu sentir yang berdampak negatif terhadap kesehatan

\section{METODE PENELITIAN}

Sampel diambil sebanyak enam SHS, yaitu tiga SHS dari Dusun Pengalusan dan tiga SHS dari Dusun Cegi. Setiap sampel diukur besar arus dan tegangan listrik yang dihasilkan.

p-ISSN:1693 - 2951; e-ISSN: 2503-2372 
Pengukuran dilakukan setiap jam dan diukur dari pukul 06.00 sampai dengan 18.00 selama tiga hari, yaitu pada tanggal 5, 12 dan 19 Februari 2017. Data hasil pengukuran ditambahkan dengan kondisi lingkungan (kelembaban udara, temperatur dan keadaan cuaca). Dari hasil pengukuran kemudian dihitung besar daya dan energi listrik yang dihasilkan SHS.

Untuk mengetahui adanya perbedaan output tegangan, arus, daya dan energi yang dihasilkan SHS, maka data dianalisis dengan menggunakan Uji Friedman, dilanjutkan dengan análisis Post Hoc dengan Uji Wilcoxon. Hasil análisis ditampilkan dalam bentuk tabel. Hasil dari uji tersebut akan menghasilkan nilai p (probabilitas) untuk mengintepretasikan hasil uji dan nilai $n$ yang menunjukan banyaknya jumlah data yang diambil pada sampel penelitian. Jika nilai $\mathrm{p}<0,05$, maka terdapat perbedaan rerata yang bermakna antara kelompok data.

\section{HASIL DAN PEMBAHASAN}

\subsection{Spesifikasi SHS}

SHS ini didistribusikan oleh PT. Citrakaton Dwitama. Setiap unit SHS terdiri dari sebuah panel surya $50 \mathrm{Wp}$, tiga buah titik lampu, baterai $70 \mathrm{Ah}$, Box Control, dan beberapa komponen pendukung.

Spesifikasi SHS di Desa Ban, Karangasem, Bali

Panel Surya $50 \mathrm{Wp}$ (ELSOL)

Daya Maksimum $\left(\mathrm{P}_{\max }\right)$

Tegangan Nominal ( $\left.\mathrm{V}_{\text {nom }}\right)$

Arus Hubung Singkat $\left(\mathrm{I}_{\mathrm{sc}}\right)$

Arus Daya Maksimum ( $\mathrm{I}_{\mathrm{mp}}$ )

Open circuit voltage $\left(\mathrm{V}_{\mathrm{oc}}\right)$

Voltage at $\mathrm{P}_{\max }$

Dimensi

Suhu Kerja

Berat Bersih

$50 \mathrm{Wp}$

$12 \mathrm{~V} \mathrm{dc}$

$3,2 \mathrm{~A} \pm 5 \%$

$2,91 \mathrm{~A} \pm 5 \%$

21,75 Vdc $\pm 5 \%$

17,95 Vdc $\pm 5 \%$

$620 \times 580 \times 40 \mathrm{~mm}$

$-40{ }^{\circ} \mathrm{C} 50{ }^{\circ} \mathrm{C}$

$5,5 \mathrm{~kg}$

BCU

Kapasitas

Tegangan

Indikator Pengisian

8-10 A

$12 \mathrm{~V}$

TLDC (ELSOL)

Jenis

Kapasitas

Tegangan

(25 - 100\%) - 3 steps

Baterai

Jenis

Kapasitas

Tegangan Nominal

Merek

Kabel Power (PV - BCU) sesuai dengan SPLN

Jenis

Ukuran

Panjang

Kabel Power (BCU - Load) sesuai dengan SPLN

Jenis

Ukuran

Lead Acid, MF- Heavy Duty 65-70 Ah $12 \mathrm{~V}$ Bervarisi
Panjang

21 meter

Tiang Module

Tinggi

$150 \mathrm{~cm}$

Diameter

$3 / 4 ”$

Finishing

Support PV Module

Besi siku

Besi pipat

Finishing

$30 \times 30 \mathrm{~mm}$

1 ”

Galvanized

\subsection{Daya dan Energi Listrik Produksi SHS}

Besar daya dan energi listrik produksi SHS dipengaruhi oleh besar dan lamanya radiasi Matahari mengenai panel surya, dan pergerakan Matahari dari arah Timur ke Barat. Selama tiga hari pengukuran rata-rata radiasi Matahari 5,38 $\mathrm{kWh} / \mathrm{m}^{2}$ dan pergerakan Matahari berada pada azimut $106^{\circ}$ (terbit) dan $254^{\circ}$ (terbenam). Umumnya keadaan cuaca pada saat pengukuran adalah berawan dengan rerata temperatur udara sebesar $25,08{ }^{\circ} \mathrm{C}\left(20,1^{\circ} \mathrm{C}-31^{\circ} \mathrm{C}\right)$.

Hasil pengukuran tegangan dan arus output SHS dapat dilihat pada Tabel I dan Tabel II, sedangkan Tabel III dan Tabel IV adalah hasil dari perhitungan untuk daya dan energi SHS. Dari hasil pengukuran dan perhitungan tersebut didapat rerata untuk tegangan, arus, daya dan energi output untuk keenam sampel.

Pada Tabel I, dengan menggunakan uji Wilcoxon, diperoleh nilai $\mathrm{p}<0,001$ untuk perbandingan tegangan output semua SHS. Dengan demikian, dapat diketahui bahwa terdapat perbedaan yang bermakna untuk tegangan yang dihasilkan setiap SHS.

Pada Tabel II, dengan menggunakan uji Wilcoxon, diperoleh nilai $\mathrm{p}<0,001$ untuk perbandingan arus output semua SHS. Dengan demikian, dapat diketahui bahwa terdapat perbedaan yang bermakna untuk arus yang dihasilkan setiap SHS.

Pada Tabel III, dengan menggunakan uji Wilcoxon, diperoleh nilai $\mathrm{p}<0,001$ untuk perbandingan daya output semua SHS. Dengan demikian, dapat diketahui bahwa terdapat perbedaan yang bermakna untuk daya yang dihasilkan oleh setiap SHS.

Pada Tabel IV, dengan menggunakan uji Wilcoxon, diperoleh nilai $\mathrm{p}<0,001$ untuk perbandingan energi output semua SHS. Dengan demikian, dapat diketahui bahwa terdapat perbedaan yang bermakna untuk besar energi yang dihasilkan oleh setiap SHS.

\begin{tabular}{rlccc} 
Bervarisi & \multicolumn{4}{c}{ UNTUK TEGANGAN OUTPUT SHS (VOLT) } \\
\cline { 2 - 5 } & Tegangan & $\mathrm{n}$ & $\begin{array}{c}\text { Median } \\
\text { (minimum-maksimum) }\end{array}$ & $p$ \\
\cline { 2 - 5 } NYYHY & SHS I & 39 & $13,02(0-14,20)$ & $<0,001$ \\
$2 \times 2,5$ mm $^{2}$ & SHS II & 39 & $11,94(0-19,8)$ & \\
7 meter & SHS III & 39 & $13,22(0-15,63)$ & \\
& SHS IV & 39 & $14,08(0-20,70)$ & \\
NYYHY & SHS V & 39 & $13,95(0-19,9)$ & \\
\cline { 2 - 5 } & SHS VI & 39 & $12,8(0-13,8)$ & \\
& & & &
\end{tabular}


TABEL II

HASIL ANALISIS FRIEDMAN - POST HOC WILCOXON UNTUK ARUS OUTPUT SHS (AMPERE)

\begin{tabular}{lccc}
\hline \multicolumn{1}{c}{ Arus } & $\mathrm{n}$ & $\begin{array}{c}\text { Median } \\
\text { (minimum-maksimum) }\end{array}$ & $p$ \\
\hline SHS I & 39 & $13,02(0-14,20)$ & $<0,001$ \\
SHS II & 39 & $11,94(0-19,8)$ & \\
SHS III & 39 & $13,22(0-15,63)$ & \\
SHS IV & 39 & $14,08(0-20,70)$ & \\
SHS V & 39 & $13,95(0-19,9)$ & \\
SHS VI & 39 & $12,8(0-13,8)$ & \\
\hline
\end{tabular}

TABEL III

HASIL ANALISIS FRIEDMAN - POST HOC WILCOXON UNTUK DAYA OUTPUT SHS (WATT)

\begin{tabular}{llcc}
\multicolumn{4}{c}{ UNTUK DAYA OUTPUT SHS (WATT) } \\
\hline Daya & $\mathrm{n}$ & $\begin{array}{c}\text { Median } \\
\text { (minimum-maksimum) }\end{array}$ & $p$ \\
\hline SHS I & 39 & $5,67(0-24,46)$ & $<0,001$ \\
SHS II & 39 & $7,00(0-47,92)$ & \\
SHS III & 39 & $8,12(0-38,14)$ & \\
SHS IV & 39 & $6,88(0-55,48)$ & \\
SHS V & 39 & $6,31(0-48,53)$ & \\
SHS VI & 39 & $8,21(0-38,77)$ & \\
\hline
\end{tabular}

TABEL IV

HASIL ANALISIS FRIEDMAN - POST HOC WILCOXON UNTUK ENERGI OUTPUT SHS (Wh)

\begin{tabular}{llcc}
\multicolumn{1}{c}{ Energi } & $\mathrm{n}$ & $\begin{array}{c}\text { Median } \\
\text { (minimum-maksimum) }\end{array}$ & $p$ \\
\hline SHS I & 39 & $7,29(0-52,15)$ & $<0,001$ \\
SHS II & 39 & $7,49(0-47,01)$ & \\
SHS III & 39 & $8,99(0-28,09)$ & \\
SHS IV & 39 & $9,96(0-44,59)$ & \\
SHS V & 39 & $8,03(0-39,14)$ & \\
SHS VI & 39 & $8,92(0-30,03)$ & \\
\hline
\end{tabular}

Gambar 2 adalah grafik daya listrik yang dihasilkan setiap SHS dalam satu hari. Dari gambar tersebut dapat dilihat bahwa terdapat perbedaan daya keluaran yang dihasilkan oleh setiap SHS. Perbedaan ini disebabkan karena arah orientasi dan sudut kemiringan panel yang kurang tepat dan berbeda Hal ini dapat disebabkan karena pada saat pemasangan panel surya terdahulu tidak memperhatikan posisi (arah dan sudut kemiringan) dimana panel surya akan dipasang. Untuk arah orientasi, sudut kemiringan dan posisi panel surya pada setiap SHS dapat dilihat pada Tabel V.

Berdasarkan dari hasil analisis dan Gambar 2, maka dapat dilakukan perbaikan. Perbaikan dilakukan dengan cara mengubah arah orientasi dan sudut kemiringan panel surya dengan sudut $8^{\circ}$ ke arah Utara. Pemilihan sudut kemiringan dan arah orientasi ini didasarkan pada lokasi lintang dari daerah tersebut.

\section{KESIMPULAN}

1. Pemasangan panel surya yang diam dengan arah orientasi dan sudut kemiringan yang berbeda akan memberikan output yang berbeda terhadap tegangan, arus, daya dan energi

2. Perbaikan pada panel surya dapat dilakukan dengan cara memperbaiki sudut kemiringan dana rah orientasi panel surya menjadi $8^{\circ}$ ke arah Utara.

\section{VI.SARAN}

Adapun saran yang dapat penulis sampaikan berdasarkan permasalahan tersebut adalah untuk perencanaan dan pembangunan SHS ke depannya yang ditujukan untuk masyarakat pedesaan agar pemasangan SHS lebih diperhatikan, seperti arah orientasi dan sudut kemiringan panel surya. Cara pemasangan SHS yang kurang tepat akan menyebabkan besar arus dan tegangan yang dihasilkan pada SHS berbeda. Hal ini akan menyebabkan besar daya dan energi yang dihasilkan SHS tidak optimal, sehingga secara tidak langsung berpengaruh terhadap kehidupan masyarakat.

Perbaikan pada SHS dapat dilakukan dengan menambahkan berpenjejak pada panel surya berdasarkan penelitian yang dilakukan oleh Syafaruddin Ch. Perbaikan pemasangan pada panel berpejejak dapat meningkatkan arus rata-rata 2,19 A dibandingkan dengan panel surya diam 1,97 A. Peningkatan nilai arus tersebut juga menyebabkan peningkatan daya rata-rata panel surya berpenjejak menjadi 39,41 W dibandingkan panel surya diam, 35,46W. Hasil ini menunjukan bahwa kinerja panel surya berpenjejak memberikan hasil yang lebih baik dari panel surya yang diam.

\section{REFERENSI}

[1] Abdulkadir, A, Teknologi Pembangkit Listrik Ramah Lingkungan: Seri Ketenagalistrikan Jidil 1. Bandung: ITB, 2017

[2] Foster, Solar Energy Renewable Energy and The Environment. Boca Raton, FL, CRC Press, 2010

[3] S Kumara Nyoman, Pembangkit Listrik Tenaga Surya Skalar Rumah Tangga Urban Dan Ketersediaanya di Indonesia, Teknik Elektro, Vol. 9 No. 1 Januari - Juni 2010.

[4] Nugraha I M A, Giriantari I A D, Kumara I N, Studi Dampak Ekonomi Dan Sosial PLTS Sebagai Listrik Pedesaan Terhadap Masyarakat Desa Ban Kubu Karangasem. Bali: CSGTEIS, 2013.

[5] Kadir,A, Energi: Sumber Daya, Inovasi, Tenaga Listrik dan Potensi Ekonomi, edisi 3. Jakarta: Universitas Indonesia, 2010.

[6] Kali, Agustinus, Analisis Program Listrik Pedesaan Dalam Meningkatkan Aktivitas Sosial Masyarakat Di Kecamatan Dolo Kabupaten Sigi. Mektek Tahun XIV, 2012.

[7] Ch Syafaruddin. Perbandingan Unjuk Kerja Antara Panel Sel Surya Berpenjejak Dengan Panel Sel Surya Diam, Teknik Elektro, Vol. 9 No.1 Januari - Juni 2010.

[8] Strong, S J, The Solar Electric House, A Design Manual For HomeScale Photovoltaic Power System. Pennsylvania: Rodale Press, 1987

[9] Nathawibawa A. A. N . B. B, Kumara I N. S., Ariastina W. G. Analisis Produksi Dari Inverter Pada Grid -Connected PLTS 1 MWP di Desa Kayubihi Kabupaten Bangli. Teknik Elektro, Vol 16, No. 1 , Januari -April , 2017. 
Daya (W)

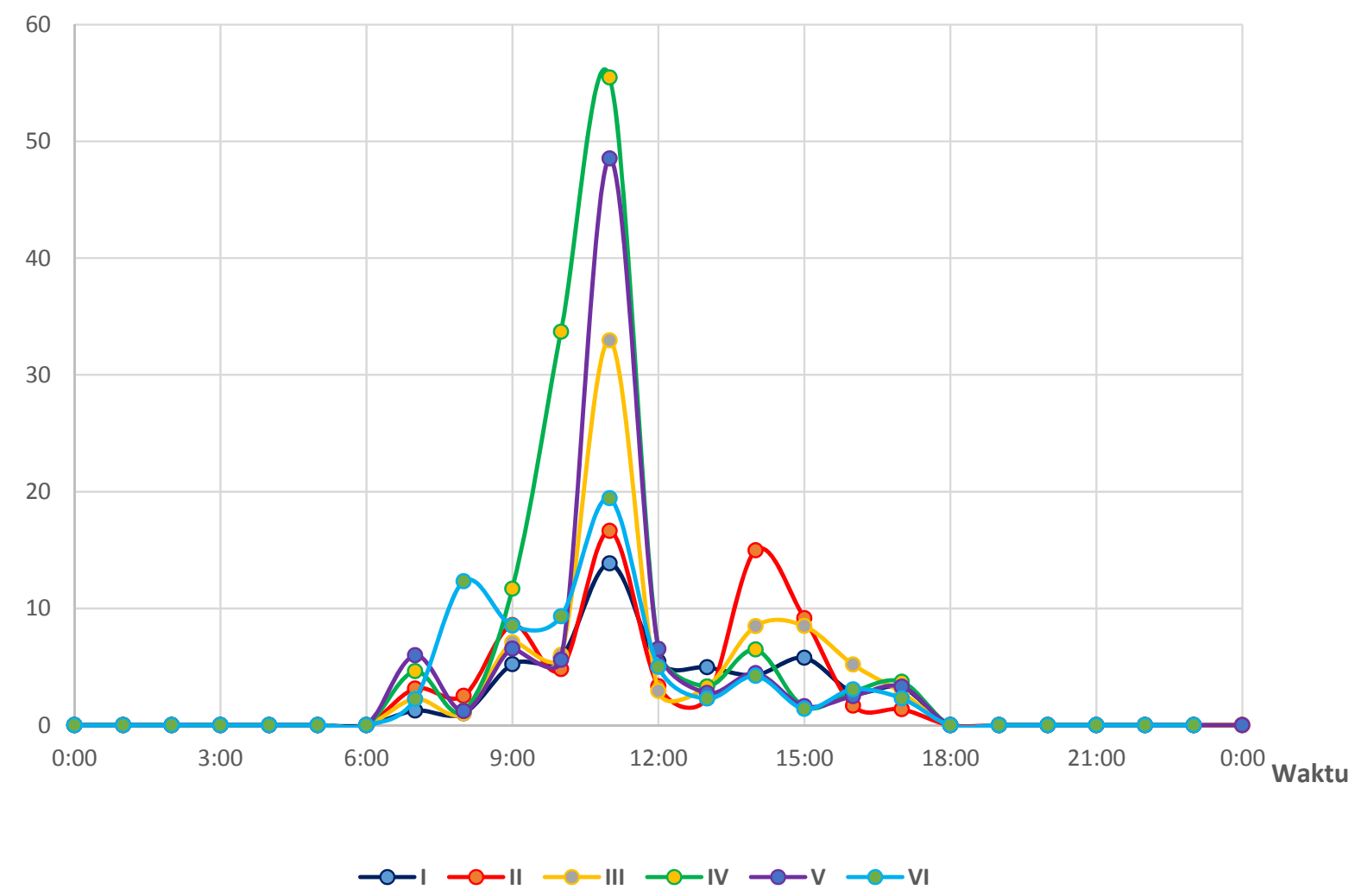

Gambar 2. Daya Produksi SHS (29 Februari 2017)

TABEL V

ARAH ORIENTASI, SUDUT KEMIRINGAN, DAN POSISI PANEL SURYA

\begin{tabular}{|c|c|c|c|c|c|}
\hline SHS & Arah Orientasi & Sudut Kemiringan & Posisi & Dusun & Keterangan \\
\hline I & Arah Panel Surya & Panel Surya & $\begin{array}{l}\text { Lintang: } \\
\text { 8¹8'12.16“ Selatan } \\
\text { Bujur : } 115^{\circ} 28^{\prime} 19.41^{\prime} \\
\text { Timur }\end{array}$ & Cegi & $\begin{array}{l}\text { Panel surya menghadap antara } \\
\text { Timur dan Selatan. } \\
350^{\circ} \text { dari Timur }\end{array}$ \\
\hline II & Arah Panel Surya & Panel Surya & $\begin{array}{c}\text { Lintang: } \\
8^{\circ} 18^{\prime} 10.82^{“} \text { Selatan } \\
\text { Bujur: } 115^{\circ} 28^{\prime} 19.99 ” \\
\text { Timur }\end{array}$ & Cegi & $\begin{array}{c}\text { Panel surya menghadap antara } \\
\text { Timur dan Utara. } \\
45^{\circ} \text { dari Timur }\end{array}$ \\
\hline & 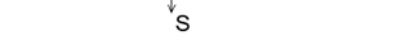 & & & & \\
\hline
\end{tabular}


Majalah Ilmiah Teknologi Elektro, Vol. 17, No. 1,Januari -April 2018

DOI: https://doi.org/10.24843/MITE.2018.v17i01.P16

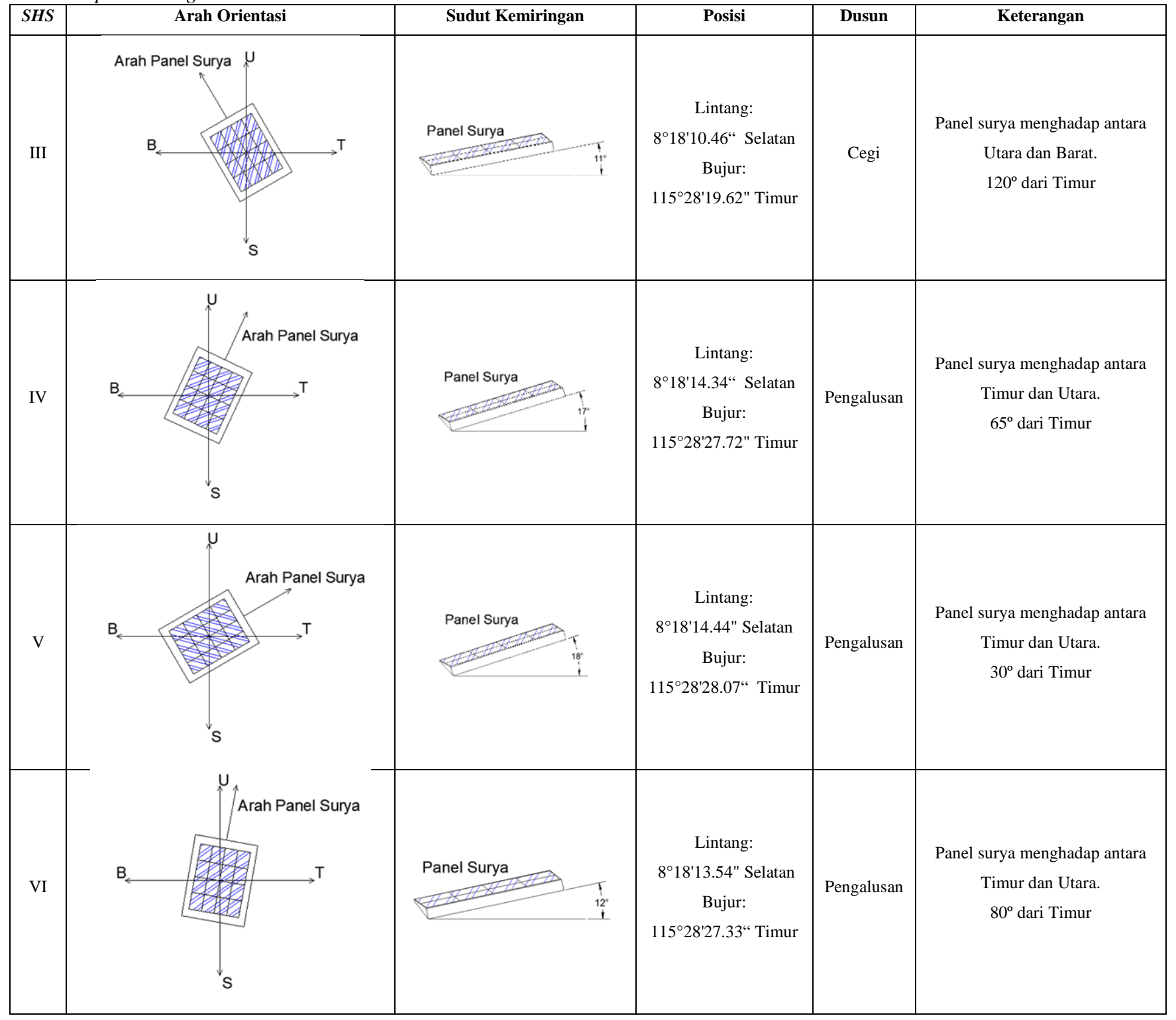

I Md Aditya Nugraha : Optimalisasi Pemasangan Panel Solar ...

p-ISSN:1693 - 2951; e-ISSN: 2503-2372 